\title{
An update on the ecological distribution of Ixodid ticks infesting cattle in Rwanda: countrywide cross-sectional survey in the wet and the dry season
}

\author{
Thomas Bazarusanga • Dirk Geysen · Jozef Vercruysse • \\ Maxime Madder
}

Received: 2 July 2007 / Accepted: 8 November 2007 / Published online: 27 November 2007

(C) Springer Science+Business Media B.V. 2007

\begin{abstract}
As part of the epidemiological studies aimed at developing an East Coast fever (ECF) immunisation control strategy, which combines an infection and treatment method with strategic tick control, a countrywide tick survey was carried out in both the dry and the wet season to determine the abundance and the dynamics of the tick populations infesting cattle in Rwanda. Six Ixodid tick species where identified from a total of 12,814 tick specimens collected. Rhipicephalus appendiculatus, the main vector of ECF was the most abundant (91.8\%) followed by Boophilus decoloratus (6.1\%) and Ambyomma variegatum $(1.2 \%)$. Few ticks from the three other less economically important Ixodid species (Rhipicephalus compositus, $R$. evertsi evertsi and Ixodes cavipalpus) were recovered. Both adult and immature stages of the most dominant tick species were found to be widespread with a year round presence. The numbers of ticks were high in low land and medium zones and declined markedly in the higher regions of Rwanda. The geographical distribution of various tick species throughout the country and their epidemiological implications are discussed.
\end{abstract}

Keywords Ixodid tick species $\cdot$ Abundance $\cdot$ Ecology $\cdot$ Distribution $\cdot$ Cattle $\cdot$ Rwanda

\section{Introduction}

Tick infestations and tick-borne pathogens are considered as one of the most economic constraint to successful cattle industry in Rwanda. Direct effects of ticks on their hosts

\footnotetext{
T. Bazarusanga

Rwanda Animal Resources Development Authority (RARDA), Kigali, Rwanda

D. Geysen · M. Madder $(\bowtie)$

Department of Animal Health, Institute of Tropical Medicine, Antwerp, Belgium e-mail: mmadder@itg.be

J. Vercruysse

Ghent University, Faculty of Veterinary Medicine, Merelbeke, Belgium
} 
include tick toxicosis, metabolic disturbances, anaemia and tick worry which can result in production losses or deaths (O'Kelly and Seithert 1969). In addition to damages caused on hides and skins, tick-bite wounds can become secondarily infected with bacteria (Lightfoot and Norval 1981). Current breed improvement programmes in Rwanda are severely hampered by the protozoan tick-borne parasites, especially East Coast fever (ECF) (Bazarusanga 1999). Although anaplasmosis, babesiosis and cowdriosis are also widespread in the country, they are of secondary importance (Bazarusanga 1999).

Control of ticks and TBDs is chiefly focused on ECF and relies on the use of costly drug treatment and acaricide applications. More recently, the use of the most environmentally compatible and cost-effective immunisation method (Mukhebi et al. 1995; Pegram et al. 1996) has been proposed as an alternative for the control of ECF. A bilateral research project between the Belgian and the Rwandan governments to identify potential ECF vaccine strains has been initiated. However, though ECF can be controlled by means of immunisation technology, which combines the infection and treatment method (Radley 1981) with strategic acaricide use, a breakdown in tick control may cause considerable losses from other tick-borne diseases.

Successful control strategy of ticks and the diseases they transmit depends on improving our understanding on the distribution and the dynamics of the tick vector in the field. There is no recent estimate on the geographical distribution of the tick species infesting cattle as well as their impact on livestock production in the country. The only available report describes the dominant distribution of three major Ixodid tick species (Rhipicephalus appendiculatus, Amblyomma variegatum and Boophilus decoloratus) (FAO 1982) as a result of small tick collections from a region-wide limited survey.

As a result of recent molecular studies (Murrell et al. 2000; Beati and Kearans 2001) the taxonomic status of the genus Boophilus has been reviewed and it has been proposed to place this genus in the genus Rhipicephalus. Considering no final decision has been taken yet this genus will still be called Boophilus throughout the study.

The present study was conducted as part of an extensive epidemiological investigation aimed at collecting baseline data for the development of an effective immunisation programme against ECF. This paper reports on the magnitude of the host's tick burdens, the between season dynamics and the geographical distribution of the variety of the tick species infesting cattle in all the four ecological regions of Rwanda.

\section{Material and methods}

\section{Study area}

Rwanda $\left(26,300 \mathrm{~km}^{2}\right)$ is a small-land locked central African country, lying between latitudes $1-3^{\circ} \mathrm{S}$ and longitudes $29-31^{\circ}$ E. It borders the Democratic Republic of Congo (DRC), Uganda, Tanzania and Burundi. Although the country is just below the equator, its high altitude (1,000-3,000 $\mathrm{m}$ above sea level) moderates the climate. The average annual temperature $\left(17-20^{\circ} \mathrm{C}\right)$ varies within the altitude ranges with small variations between the rainy and the dry season. The country enjoys high rainfall (October-June) followed by a short dry period (July-September). The average monthly rainfall of $85 \mathrm{~mm}$ supports a wide range of crops and vegetation. Mountain ranges and high land plateaus dominate the relief of the country. Based on altitude and the climate, four major agro ecological zones (AEZs) have been defined (Table 1 and Figs. 1, 2): The High land zone referred to as AEZ 1 is found in the northern cold and high rainfall regions at $1950 \mathrm{~m}$ 
Table 1 Description of the 4 agro-ecological zones of Rwanda

\begin{tabular}{lllll}
\hline $\begin{array}{l}\text { Agro-ecological } \\
\text { zones (AEZ) }\end{array}$ & Altitude & $\begin{array}{l}\text { Temperature } \\
\left({ }^{\circ} \mathrm{C}\right)\end{array}$ & $\begin{array}{l}\text { Annual rainfall } \\
(\mathrm{mm})\end{array}$ & $\begin{array}{l}\text { Period of rain } \\
\text { in a year }\end{array}$ \\
\hline 1: High land & $>1,950 \mathrm{~m}$ & $14-17$ & $>1400$ & $\begin{array}{l}\text { September-July } \\
\text { 2: Central high plateau }\end{array}$ \\
$\begin{array}{ll}\text { 3: Western high plateau } \\
\text { 4: Eastern plateau }\end{array}$ & $1,650-1,950$ & $18-20$ & $1,200-1,300$ & $\begin{array}{l}\text { October-June } \\
\text { October-June } \\
\text { November-May }\end{array}$ \\
\hline
\end{tabular}

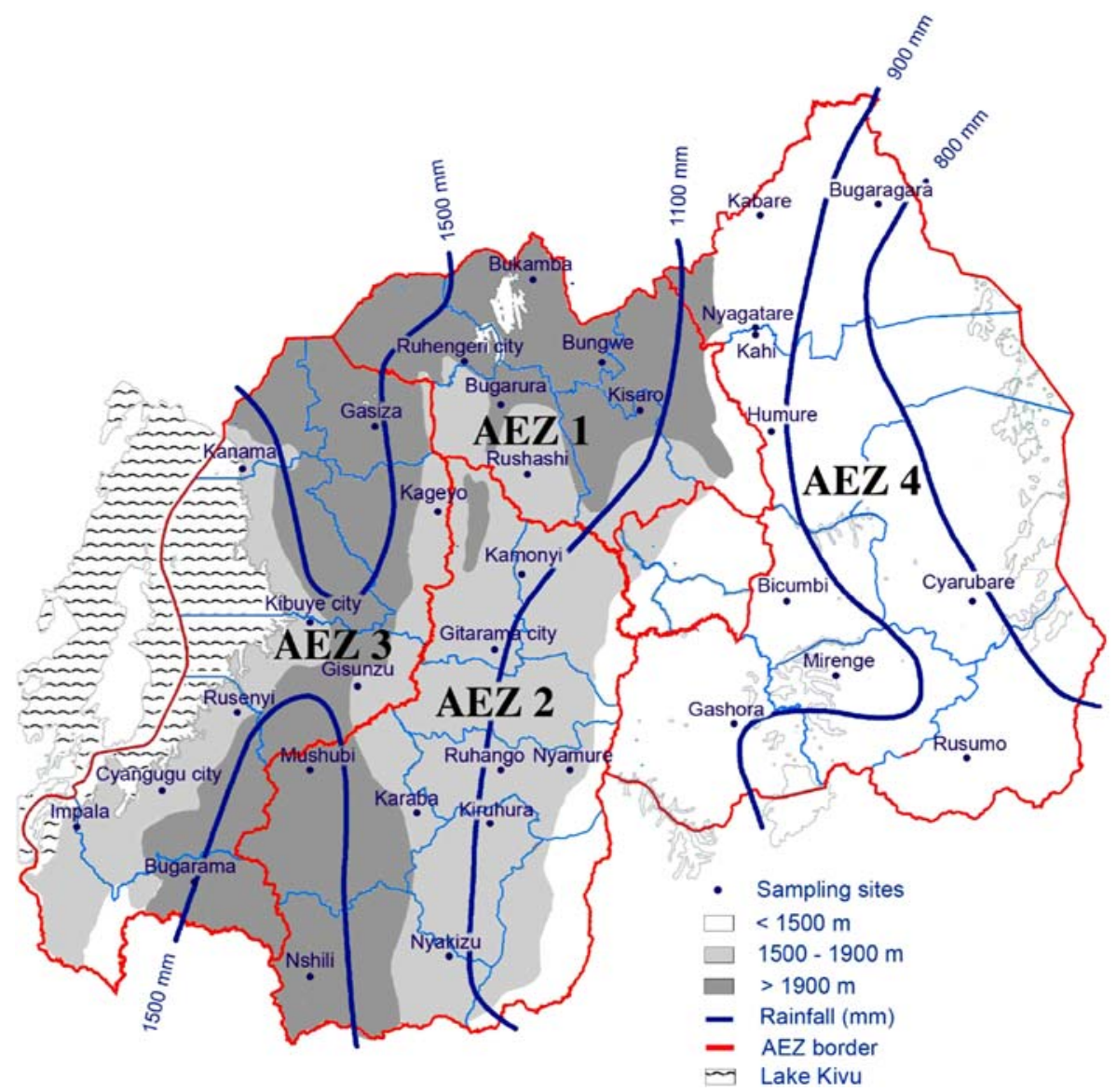

Fig. 1 Bioclimatic zones and survey localities in the country

altitude. South to AEZ 1, the large central high plateau lies between 1,550-1,950 m above the sea level and extends in the south-western part of the country (AEZ 2 and 3). Lake Kivu, which separates Rwanda from the Democratic Republic of Congo, moderates the climate in the western high plateau (AEZ 3) while a relatively colder climate prevails in the central high plateau (AEZ 2). The eastern plateau (AEZ 4) ranges between 1,000 and $1,550 \mathrm{~m}$ altitude with a number of high elevations. Cattle constitute the main livestock and are raised in all the four agro-ecological zones under different management 

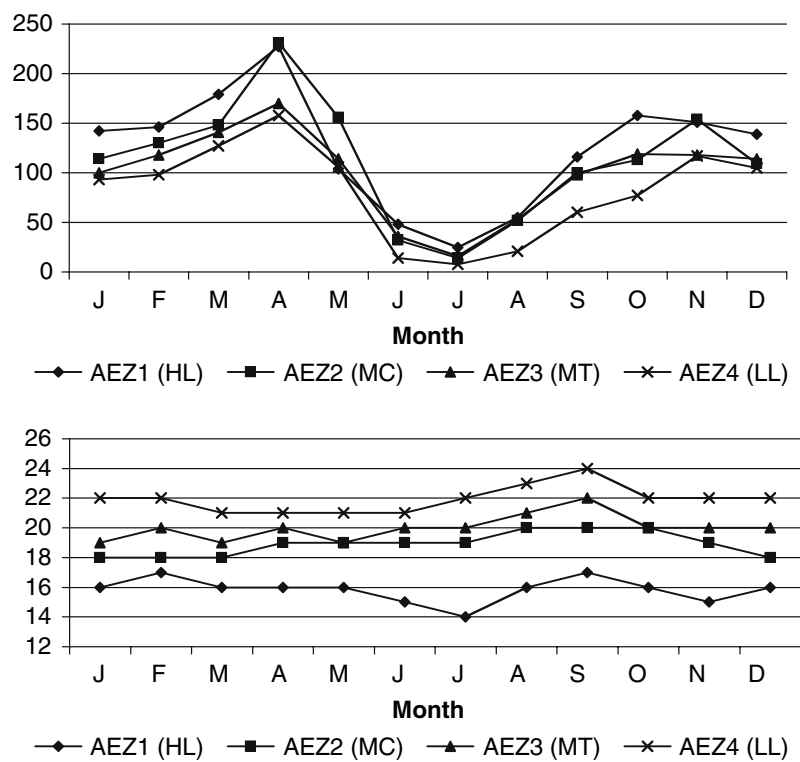

Fig. 2 Monthly rainfall (above) and temperature (below) data of the four agro ecological zones

systems. The eastern plateau zone (AEZ 4) is the most important cattle area in Rwanda, holding $40 \%$ of the national herd (estimated at a total of 1,000,000 heads of cattle) whereas in the western high plateau (AEZ 3), a limited number (13\%) is recorded just like in the highly populated high land (AEZ 1) part of the country. Although indoor management strategy (or zero grazing) is the rule in Rwanda, the higher the number of cattle in the region, the less the indoor husbandry policy is successfully applied with the most communal grazing systems found in eastern plateau and a gradual shift to a more developed zero grazing management system in high land zones.

Tick collections and identification

Ticks were collected during the dry period (August-September 2002) and the wet season (April-May 2003) surveys from a total of 204 (102 per season) randomly selected cattle in the four bio-climatic zones. In each zone, an average number of 9-12 farms were randomly chosen. A half body tick collection was performed on 36 animals in the high land, 54 in the central high plateau, 54 in the western high plateau and 60 in the eastern plateau. All visible ticks were collected by the means of fine-forceps after the animals had been restrained on the pen floor. Because of their small size, a hand was thoroughly passed throughout the hair of the animal to collect the maximum of the immature stages. The ticks from each animal were preserved in separate labelled vials containing $70 \%$ ethanol, and subsequently counted and identified to genus and species level using a standard stereomicroscope and with the aid of an identification guide of Walker et al. (2003). Part of the specimens was brought to the Institute of Tropical Medicine of Antwerp for subsequent re-identification. Sex was determined in all adult ticks collected. Larvae and nymphs were classified in the same group as immature stages. 


\section{Results}

The species and numbers of ticks collected in the different agro-ecological zones are summarised in Tables 2 and 3. A total of 12,814 ticks belonging to six species were collected on the same number of animals (102) during the dry season (6101) and the wet season (6713) surveys in the four ecological zones of Rwanda. Except for the dominant position of $R$. appendiculatus, which outnumbered $(91.84 \%)$ all others in the total tick collection, B. decoloratus $(6.07 \%)$ and A. variegatum $(1.24 \%)$ were also commonly collected. The other rhipicephalids namely $R$. compositus $(0.31 \%)$ and $R$. evertsi evertsi $(0.46 \%)$ together with I. cavipalpus $(0.08 \%)$ were incidental or sporadic infestations.

\section{Rhipicephalus appendiculatus}

The abundance of adult $R$. appendiculatus was higher at lower altitudes ranging from 11 ticks per animal in AEZ 1 up to 72 ticks in AEZ 4. Ticks were active throughout the year although variation was observed between the different zones. The activity of immature ticks of this species was mainly during the wet season. Similarly to the adults, immatures were less abundant at higher altitudes (AEZ 1). The sex ratio (males:females) was (1:0.7).

\section{Boophilus decoloratus}

The number of adult $B$. decoloratus ticks collected was relatively low ranging from less than one tick per animal in AEZ 4 up to nine ticks in AEZ 3. Both immature and adult ticks were most abundant at intermediate altitudes (AEZ 2 and 3). No seasonal pattern could be found for this species. The sex ratio (males:females) was (1:2.4). This one host tick had the highest adult: immature ratio (1:0.64).

\section{Amblyomma variegatum}

Adults of A. variegatum were predominant in the dry season and both adults and immatures quasi-absent in the cold high land zones (AEZ 1). The average number of adult A. variegatum ticks was less than two ticks per animal. Immature stages were predominant in the wet season. The sex ratio (males:females) was (1:0.5).

Other rare species

The activity patterns of $R$. compositus, $R$. evertsi evertsi and I. cavipalpus are difficult to describe due to the low numbers of ticks collected for these species (Table 3). Ixodes cavipalpus was however only collected in the dry season (only 9 ticks on 204 animals).

Of the 39 (19\%) animals found uninfested, a large proportion (21) belonged to the high land zones. The maximum number of tick infestation (559) on a single animal was found in the eastern plateau region. The average tick burdens per animal were significantly lower in the high land (13 ticks) as compared to 68-78 ticks (Table 3 ) in the other areas. All preimaginal stages (11\%), which include larvae and nymphs, constituted $8 \%$ of the dry seasonal sample whereas in the wet season, they represented $3 \%$. 


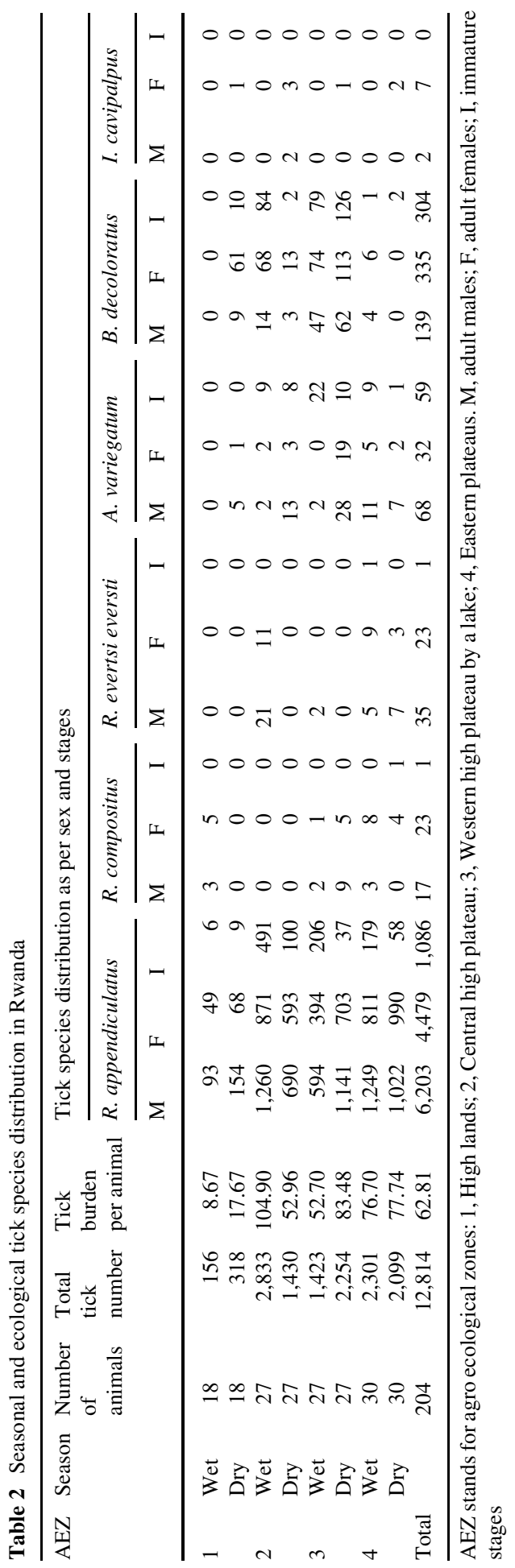




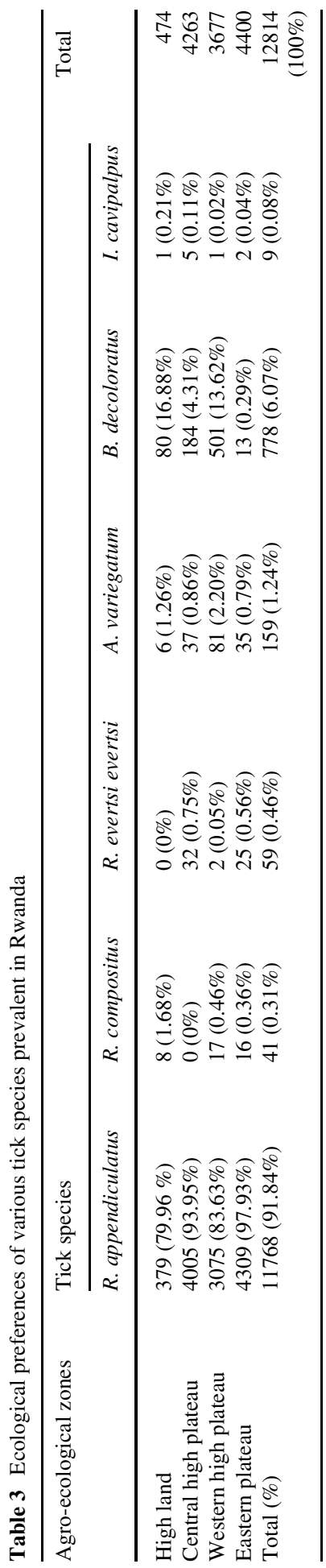




\section{Discussion}

Tick species diversity

The results obtained are consistent with previous reports as far as the presence of important cattle ticks throughout the region (Paling and Geysen 1981; Kaiser et al. 1988), but this is the first study so far performed in Rwanda on an ecological and seasonal basis. Three main species, $R$. appendiculatus, B. decoloratus and A. variegatum were commonly collected whereas the remaining group of three other species ( $R$. compositus, $R$. evertsi evertsi and I. cavipalpus) represented incidentally or sporadic infestations. It is rare to find more than six tick species infesting their host in a given ecological zone (Punyua et al. 1991). No recent information on ticks is available in Rwanda and our knowledge is mainly based on unpublished data and personal communications. However, East Coast fever transmitted by the brown ear tick ( $R$. appendiculatus) and Anaplasma marginale along with Babesia bigemina transmitted by $B$. decoloratus are described as the major tick-borne pathogens affecting cattle in Rwanda (FAO 1982; Bazarusanga 1999, Bazarusanga et al. 2007). This clearly corroborates our results and confirms earlier reports on major tick occurrences in the country.

It is generally admitted that potential distributions of tick species are principally determined by the bio-climatic envelop and the presence of suitable hosts (Cummings 2002; Olwoch et al. 2003; Estrada-Peña 2003). The three dominant tick species are therefore suggested to be in equilibrium with the current climate. However, Pearson and Dawson (2003) reported that while the bio-climatic approach could provide a useful first approximation, many other factors such as the dispersal ability by host and vegetation might have a potential impact in the mapping of various tick species. In the present study, it is hypothesised that with massive influx of cattle populations in Rwanda during the post war period, introduction of new tick species may have occurred. The smaller populations of I. cavipalpus together with the rhipicephalids other than $R$. appendiculatus may not only be an indication of the known poor host specificity in those species (Hlatshwayo et al. 2002), but also the unsuitability of the habitat for their development and survival. Hutchinson (1957) defined the fundamental ecological niche as comprising those environmental conditions within which a species can survive and grow. It is usually accepted that the climate cannot only determine the tolerance range of a species, but also involves selection against phenotypes that are poorly adapted to local conditions (Davis and Shaw 2001). The small numbers recovered might be considered as accidental importations of species that did not find their ecological preference.

Rhipicephalus evertsi evertsi has been the most studied species and is more common in regions receiving between 400 and 1,000 mm of rainfall (Maclvor and Horak 2003). Similarly, the climatic requirements for I. cavipalpus ranges from 900 to $1,000 \mathrm{~mm}$ mean annual rainfall and 3 months continuous dry season in Uganda to 500-750 $\mathrm{mm}$ in Tanzania and Kenya (Matthysse and Colbo 1987). High moisture values recorded in most regions of Rwanda may have been critical for the development and establishment of both species. Although their numbers were much lower, $R$. evertsi evertsi contributed to the tick worry problems by causing open wounds at their aggregation sites.

Abundance, phenology and relative distribution

In addition to the relatively important variety in tick species, the tick burden in the country was found very high with a negative gradient from the eastern plateau to the high land zones. The particularly higher population pressure on land in the high land, which leads to 
more intensification of the livestock production, coupled with unfavourable climatic conditions at an altitude of over $1,950 \mathrm{~m}$, undoubtedly resulted in low tick survival and infestations. The observation of lower tick infestations in high land correlates with earlier findings from Paling and Geysen (1981), where high tick burdens were recorded in the whole of Rwanda except at higher altitudes. Most regions of the country provide an optimal temperature for the development of all tick instars on a year round basis.

The superabundant pattern recorded in $R$. appendiculatus seems to dictate the entire picture of the tick population in Rwanda. This relatively dominant position in all the zones of the country reflects the ecological plasticity of this species, which is most frequently found between 1,000 $\mathrm{m}$ and 2,000 $\mathrm{m}$ altitude (Berggren 1978). The presence of ticks throughout the year indicates that $R$. appendiculatus has more than one generation a year as is observed in more equatorial regions of its distribution where no synchronisation of the life cycle is needed (Madder et al. 2002).

Boophilus decoloratus, the second most important species also had a ubiquitous distribution with a preference for intermediate altitudes as previously recorded by Matthysse and Colbo (1987). The later authors describe the presence of $B$. decoloratus in Uganda at elevations from just over $600 \mathrm{~m}$ to $2,300 \mathrm{~m}$. The lack of a seasonal pattern and the simultaneous occurrence of both adult and immature ticks have been recorded in many other countries in eastern and northern part of southern Africa (Matthysse and Colbo 1987; Berkvens et al. 1998).

In the present study, special care was taken in the identification of Boophilus spp. It is of interest to note the absence of $B$. microplus, whose trend to invade new areas previously colonised by $B$. decoloratus has been demonstrated by various authors (Theiler 1962; MacLeod and Mwanaumo 1978; Berkvens et al. 1998; Tønnesen et al. 2004). The spread of B. microplus has been recorded in neighbouring Tanzania (Lynen, personal communication) and it is believed that there are large geographic areas at risk of colonization by B. microplus in Africa (Estrada-Peña et al. 2006).

While A. variegatum is known to occur in semi-arid as well as humid regions (Yeoman and Walker 1967), light infestations were found in this study and the species was virtually absent in highly humid zones. This is most likely related with the high altitude in this zone (AEZ 1). In neighboring Uganda, A. variegatum was also only found up to altitudes of $1800 \mathrm{~m}$ (Matthysse and Colbo 1987) corresponding to the altitude range in AEZ 2.

Our results are in agreement with observations in Zimbabwe where A. variegatum previously occurred in drier lowveld areas surrounding the Zambezi valley (Norval 1994) but later on established in western parts of the highveld plateau and started to encroach on the predominantly heartwater-free central and eastern highveld regions (Peter et al. 1998). Amblyomma variegatum showed similar climatic preference as $R$. appendiculatus and was almost absent at higher elevations. No seasonal differences in tick numbers were observed in contrast to populations in southern Africa where this species is characterized by a strict seasonal activity with a morphogenetic diapause in the engorged female ticks (Pegram et al. 1988).

Influence of the abundance of $R$. appendiculatus on the epidemiology of ECF and implications for control strategy

In most regions of Rwanda, the high number of $R$. appendiculatus ticks found throughout the year coupled with high seroprevalence (Bazarusanga et al. 2007) guarantee a more stable endemic situation. Most cattle farmers have small herds of indigenous cattle kept under extensive management systems with little or no tick control. The low innate susceptibility 
together with rapid development of immunity results in little or no loss in productivity or in mortality. Only the calf population usually kept indoors for almost 6 months are at risk. An earlier exposure of calves to ticks would probably decrease mortality in young animals.

However, the small-scale cross-bred dairy production units kept under intensive and semi-intensive management conditions with variable and irregular acaricide application are becoming increasingly significant. Infection therefore occurs on a regular basis and because of the high susceptibility of most of the herds, affected animals suffer a high case-fatality.

On the other hand pure-bred dairy production units which use highly susceptible exotic (Friesian) cattle as contributors of milk to growing urban populations are characterised by very good intensive management and regular acaricide application. Under these circumstances, the transmission of $T$. parva by $R$. appendiculatus is interrupted. The incidence of $\mathrm{ECF}$ in the peri-urban modern farming systems is significantly reduced.

An unstable epidemiological situation prevails in high land areas where cattle population immunity to $T$. parva was found low due to the periodic unsuitability of the climate for survival and development of $R$. appendiculatus. Because of low tick challenge coupled with widespread zero grazing management system practiced in the high land zones, longer age-at-first-contact period are observed. These conditions would normally induce more clinical cases of ECF with possible outbreaks since more susceptible animals are present. Nevertheless, losses from ECF are considerably reduced due to the efficient animal care by farmers in this area. Clinical cases in affected cattle are usually recognised early through good management, and animals are treated with anti-theilerial compound. An ECF outbreak situation occurs however when animals from the high land zones are shifted in the more endemic regions of the country.

Unbalanced ratios between mature and immature stages and between males and females

In this survey, lower infestation of immature stages on cattle compared to adult stages was not unexpected, since host-specificity of the pre-imaginal stages is generally very low (Norval 1982). Furthermore, the method used to collect immature stages was not the most efficient. More larvae and nymphs would probably have been collected had the cattle hair been combed. In previous studies, a poor correlation between larval and adult results has also been observed and was due to the differential efficiency in sampling methods (Randolph and Rogers 1997; Zieger et al. 1998). The field data can only give relative estimates of the abundance of the different life-stages of the tick on their hosts.

To correct the under-counting of the immature stages, Randolph $(1994,1997)$ proposed a correction by multiplying all the actual counts of larvae by 100 and those of nymphs by 10 for three host ticks. However, the particular life cycle of various tick species should be a key variable in whatever step taken for adjustments in the different development stages. In the three most prevalent species, differences in adult:immature stage ratios were noted. The highest ratio was found in the one host $B$. decoloratus species while the three hosts' $R$. appendiculatus species had the lowest ratio probably due to the relatively higher likelihood in off-host dependent mortality in the two or three host tick species.

Moisture appears to be critical for the off-host developmental stages since mortality is highest where it is both too dry and too wet. Although ticks are found on their host on a year round basis in the equatorial regions, Randolph and Rogers (1997) stated a discernible seasonality especially in the immature ticks. Lower numbers in the immature stages found during the wet season in Rwanda are in line with earlier reports and may be explained by high-moisture dependant mortality during the rain period. However, it is believed that seasonal patterns in equatorial areas are not only determined by abiotic factors (Randolph 
1994), superimposed biotic factors such as the recent changes in the managerial system in Rwanda with most animals kept indoors may act negatively on the probability for the larvae and nymphs to successfully contact a host.

Despite the low number of immature stages, the present results are consistent with the general agreement in relation to the overlapping pattern in the activity of all tick instars earlier described in the region (McCulloch 1968; Paling and Geysen 1981; Kaiser et al. 1982). This would mean an almost constant presence of transmitting instars of TBDs throughout the whole year.

Normal sex ratio's (male:female, 2:1) were found in $R$. appendiculatus and A. variegatum. However, more females were found in B. decoloratus. The small size of the males, which is characteristic for this species, might have influenced the sampling efficacy.

It can be stated by concluding that $R$. appendiculatus is the predominant tick species in Rwanda and close to the geographical centre of its distribution. As in many parts of eastern and central Africa, tick populations experience no prolonged dry season and all stages are present throughout the year in the whole country, except in the mountainous marginal regions.

Acknowledgement This study was made possible through the financial support of the VLIR and the assistance from technical staff of the National Veterinary Laboratory of Rwanda (Francisca R. Mudaheranwa, Jeanne M. Uwamahoro, Ernest Munyagishali and J. Claude Ndolimana). We are also thankful to Dr Rutagwenda Theogen and Dr Gafarasi Isidore (RARDA) for logistic support and useful advices.

\section{References}

Bazarusanga T (1999) Molecular characterisation of T. parva parasites in the field of Rwanda. MSc. Thesis 85, Institute for Tropical Medicine, Antwerp, Belgium

Bazarusanga T, Vercruysse J, Marcotty T, Geysen D (2007) Epidemiological studies on Theileriosis and the dynamics of Theileria parva infections in Rwanda. Vet Parasitol 143:214-221

Beati L, Keirans JE (2001) Analysis of the systematic relationships among ticks of the genera Rhipicephalus and Boophilus (Acari: Ixodidae) based on mitochondrial 12S ribosomal DNA gene sequences and morphological characteristics. J Parasitol 87:32-48

Berggren SA (1978) Cattle ticks in Malawi. Vet Parasitol 4:289-297

Berkvens DL, Geysen DM, Chaka G, Madder M, Brandt JRA (1998) A survey of the Ixodid ticks parasitizing cattle in the Eastern province of Zambia. Med Vet Entomol 12:234-268

Cummings GS (2002) Comparing climate and vegetation as limiting factors for species ranges of African ticks. Ecology 83:255-268

Davis MB, Shaw RG (2001) Range shifts and adaptive responses to quaternary climate change. Science 292:673-679

Estrada-Peña A (2003) Climate change decreases habitat suitability for some tick species (Acari: Ixodidea) in South Africa. Onderstepoort J Vet Res 70:79-93

Estrada-Peña A, Bouattour A, Camicas J-L, Guglielmone A, Horak I, Jongejan F, Latif A, Pegram R, Walker AR (2006) The known distribution and ecological preferences of the tick subgenus Boophilus (Acari: Ixodidae) in Africa and Latin America. Exp Appl Acarol 38:219-235

FAO (1982) Rwanda. Epizootiology and control of tick-borne diseases. Technical report No. 1. AG: RW/ 77/ 006. Food and Agriculture Organisation, Rome $78 \mathrm{pp}$

Hlatshwayo M, Mbati PA, Dipeolu OO (2002) Seasonal abundance of adult ixodid ticks infesting cattle belonging to resource-limited farmers in the north-eastern Free State Province of South Africa. Onderstepoort J Vet Res 69:1-6

Hutchinson GE (1957) Concluding remarks. In population studies: animal ecology and demography. Cold spring Harbor Symposia on Quantitative Biology, vol 22. Cold Spring Harbor Laboratory Press

Kaiser MN, Sutherst RW, Bourne AS (1982) Relationship between ticks and Zebu cattle in Southern Uganda. Trop Anim Health Prod 14:63-74

Kaiser MN, Sutherst RW, Bourne AS, Gorissen L, Floyd RB (1988) Population dynamics of ticks on Ankole cattle in five ecological zones in Burundi and strategies for their control. Prev Vet Med 6:199-222 
Lightfoot CJ, Norval RAI (1981) Tick problems in Wildlife in Zimbabwe. 1. The effects of tick parasitism on wild ungulates. S Afr J Wildlife Res 60:253-274

MacIvor KM de F, Horak IG (2003) Ixodid ticks of Angora and Boer goats, grysbok, common duikers, kudus and scrub hares in Valley Bushveld in the Eastern Cape Province, South Africa. Onderstepoort J Vet Res 70:113-120

MacLeod J, Mwanaumo B (1978) Ecological studies of ticks (Acari: Ixodidae) in Zambia. IV: Some anomalous infestation patterns in the Northern and Eastern regions. Bull Entomol Res 68:409-429

Madder M, Speybroeck N, Brandt J, Tirry L, Hodek I, Berkvens D (2002) Geographic variation in diapause response of adult Rhipicephalus appendiculatus ticks. Exp Appl Acarol 27:209-221

Matthysse JG, Colbo MH (1987) The Ixodid ticks of Uganda. Entomological Society of America. College Park, Maryland

McCulloch B, Kalaye WJ, Tungaraza R, Suda B'QJ, Mbasha EMS (1968) A study of the life history of the tick Rhipicephalus appendiculatus - the main vector of East Cost fever - with reference to its behaviour under field conditions and with regard to its control in Sukumaland, Tanzania. Bull Epiz Dis Afr 16:477500

Mukhebi AW, Kariuki DP, Mussukuya E, Mullins G, Ngumi PN, Thorpe W, Perry BD (1995) Assessing the economic impact of immunisation against East Coast fever: a case study in Coast Province, Kenya. Vet Rec 137:17-22

Murrell A, Campbell NJH, Barker SC (2000) Phylogenetic analyses of the Rhipicephaline ticks indicate that the genus Rhipicephalus is paraphyletic. Mol Phylogen Evol 16:1-7

Norval RAI (1982) The ticks of Zimbabwe. IV. The genus Hyalomma. Zimbabwe Vet J 13:2-10

Norval RAI (1994) Factors affecting the distributions of the ticks Amblyomma hebraeum and A. variegatum in Zimbabwe: implications of reduced acaricide usage. Exp Appl Acarol 18:383-407

O’Kelly JC, Seifert GW (1969) Relationship between resistance to Boophilus microplus, nutritional status, blood composition of Shorthorn x Hereford cattle on high and low planes of nutrition. Australian J Biol Sci 22:1497-1506

Olwoch JM, Rautenbach CJ de W, Erasmus BFN, Englebrecht BFA, Jaarsveld AS (2003) Simulating tick distributions over sub-Saharan Africa: the use of observed and simulates climate surfaces. J Biogeogr 30:1221-1232

Paling RW, Geysen D (1981) Observations on Rwanda strains of Theileria parva and the value of T. parva Nyakizu as a possible vaccine strain. In: Irvin AD, Cunningham MP, Young AS (eds) Advances in the control of Theileriosis: Proceedings of an international conference held at ILRAD, Nairobi, 9-13 February, 1981. Martinus Nijhoff Publishers, The Hague, pp 238-241

Pearson RG, Dawson TP (2003) Predicting the impacts of climate change on the distribution of species: are bioclimate envelope models useful? Global Ecol Biogeogr 12:361-371

Pegram RG, James AD, Bamhare C, Dolan TT, Hove T, Khanai GK, Latif AA (1996) Effects of immunisation against Theileria parva on beef cattle productivity and economics of control options. Trop Anim Health Prod 28:99-111

Pegram RG, Mwase ET, Zivkovic D, Jongejan F (1988) Morphogenetic diapause in Amblyomma variegatum (Acari: Ixodidae). Med Vet Entomol 2:301-307

Peter TF, Perry BD, O’Callaghan CJ, Medley GF, Shumba W, Madzima W, Burridge MJ, Mahan SM (1998) Distributions of the vectors of heartwater, Amblyomma hebraeum and Amblyomma variegatum (Acari: Ixodidae), in Zimbabwe. Exp Appl Acarol 22:725-740

Punyua DK, Latif AA, Nokoe S, Capstick PB (1991) Tick (Acari: Ixodidae) infestations on Zebu cattle in Western Kenya: seasonal dynamics of four species of ticks on traditionally managed cattle. J Med Entomol 28:630-636

Radley DE (1981) Infection and treatment method of immunization against Theileriosis. In: Irvin AD, Cunningham MP, Young AS (eds) Advances in the control of Theileriosis: Proceedings of an international conference held at ILRAD, Nairobi, 9-13 February, 1981. Martinus Nijhoff Publishers, The Hague, pp 227-236

Randolph SE, Rogers DJ (1997) A generic population model for the African tick Rhipicephalus appendiculatus. Parasitology 115:265-279

Randolph SE (1994) Population dynamics and density-dependant seasonal mortality indices of the tick Rhipicephalus appendiculatus in Eastern and Southern Africa. Med Vet Entomol 8:351-368

Randolph SE (1997) Abiotic and biotic determinants of the seasonal dynamics of the tick Rhipicephalus appendiculatus in South Africa. Med Vet Entomol 11:25-37

Theiler G (1962) The Ixodidae parasites of vertebrates in Africa South of Sahara (Ethiopian region), Projects S 9958. Report to the Director of Veterinary services, Onderstepoort 
Tønnesen MH, Penzhorn BL, Bryson NR, Stoltz WH, Masibigiri (2004) Displacement of Boophilus decoloratus by Boophilus microplus in the Soutpansberg Region, Limpopo Province, South Africa. Exp Appl Acarol 32:199-208

Walker AR, Bouattour A, Camicas J-L, Estrada-Peña A, Horak IG, Latif AA, Pegram RG, Preston PM (2003) Ticks of domestic animals in Africa: a guide to identification of species. Bioscience Reports, UK

Yeoman GH, Walker JB (1967) The Ixodid ticks of Tanzania. Commonwealth Institute of Entomology, London

Zieger U, Horak IG, Cauldwell AE, Uys AC, Bothma J, Du P (1998) The effect of chemical tick control on cattle on free-living ixodid ticks and on ticks parasitic on sympatric Impala in the Central Province, Zambia. S Afr J Wildlife Res 28:10-15 